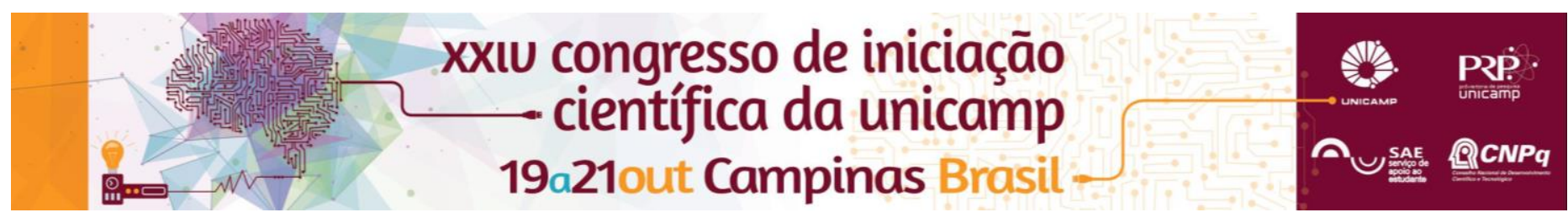

\title{
AVALIAÇÃO DA VELOCIDADE DE DESLOCAMENTO E POTÊNCIA DE MEMBROS INFERIORES EM ATLETAS DE FUTEBOL FEMININO DAS CATEGORIAS SUB 15 E SUB 17.
}

\author{
Matheus do Valle Liasch*, João Paulo Borin.
}

\section{Resumo}

O presente estudo buscou avaliar e comparar no início e final de oito semanas de treinamento a velocidade de deslocamento em $10 \mathrm{~m}$ e $30 \mathrm{~m}$ e a potência de membros inferiores de 20 futebolistas do sexo feminino, das categorias sub-15 e sub-17. A partir dos dados coletados conclui-se que houve sensível melhora na velocidade em $10 \mathrm{~m}$ na categoria sub-15 e em $30 \mathrm{~m}$ nas duas categorias. A potência mostrou melhora significativa $(p<0,05)$ na categoria sub- 15 .

\section{Palavras-chave}

treinamento desportivo, organização do treinamento, metodologia do treinamento.

\section{Introdução}

O futebol feminino tem sido considerado uma modalidade de caráter intermitente e necessita de um desempenho satisfatório das diferentes capacidades biomotoras, principalmente a velocidade de deslocamento e a potência de membros inferiores, para realização de diferentes ações motoras características da modalidade como chute, passe, cabeceios, entre outras. Porém notase na literatura escassez de informações quanto a organização de tais capacidades durante treinamento.

\section{Resultados e Discussão}

Participaram do estudo 20 atletas do sexo feminino, com idade entre 14 e 17 anos $(165,05 \pm 7,94 \mathrm{~cm} ; 59,14 \pm 9,30$ $\mathrm{kg})$. Durante oito semanas, todos os conteúdos dos treinamentos e jogos realizados foram anotados e classificados de acordo com proposta de Gomes, Souza (2008) em funcional e neuromuscular. Neste mesmo período, as futebolistas passaram por dois momentos de avaliações: primeira semana de treinamento (M0) e na $8^{\text {a }}$ semana de treinamento (M1), nas capacidades de velocidade de deslocamento em 10 e 30 metros e na potência de membros inferiores, utilizando a técnica countermovement jump. Após a coleta dos dados, os valores foram transcritos em planilha específica e armazenados em banco computacional, produzindo-se informações no plano descritivo (média e desvio padrão) e no inferencial, após verificar a normalidade dos dados aplicou-se o teste $\mathrm{T}$ de Student para amostras pareadas $(p<0,05)$

A partir da organização do treinamento de acordo com a distribuição do conteúdo de treinamento (tabela 1) percebe-se predomínio do neuromuscular $(53,3 \%)$ sobre o funcional $(46,7 \%)$ com destaque para força especial e velocidade de movimento. Quanto ao comportamento das capacidades biomotoras (tabela 2) nota-se sensível melhora $(p>0,05)$ para velocidade em 10 metros no sub 15 e velocidade em 30 metros nas duas categorias. Houve também uma pequena queda no desempenho da velocidade $(p>0,05)$ em 10 metros para a sub 17. A potência apresentou melhora significativa $(p<0,05)$ para sub 15 e sensível decréscimo $(p>0,05)$ na categoria sub 17 .
Tabela 1. Frequência absoluta e relativa das sessões de treinamento segundo capacidade biomotora predominante.

\begin{tabular}{lcc}
\hline Capacidade biomotora & \multicolumn{2}{c}{ Sessões de treino } \\
\cline { 2 - 3 } & \multicolumn{2}{c}{ Minutos } \\
\hline Neuromuscular & 2925 & 36,1 \\
$\quad$ Força Especial & 1120 & 13,8 \\
$\quad$ Velocidade de Movimento (Agilidade) & 275 & 3,4 \\
$\quad$ Coordenação Geral & 4320 & 53,3 \\
$\quad$ Total Neuromuscular & & \\
Funcional & 280 & 3,5 \\
$\quad$ Resistència Geral & 3270 & 40,3 \\
$\quad$ Resistència Especial & 240 & 3,0 \\
$\quad$ Resistência de Velocidade & 3790 & 46,7 \\
$\quad$ Total Funcional & 8110 & 100 \\
\hline Total Geral &
\end{tabular}

Tabela 2. Média e desvio padrão das variáveis estudadas nas diferentes categorias segundo momento avaliado.

\begin{tabular}{c|c|c|c|c|c|c}
\hline \multirow{2}{*}{ Variável } & \multicolumn{2}{|c|}{ Sub 15 } & \multirow{2}{*}{ Resultado } & \multicolumn{2}{|c|}{ Sub 17 } & Resultado \\
Estudada & M0 & M1 & \multirow{2}{*}{ Estatístico } & M0 & M1 & Estatístico \\
& & & & & & \\
\hline V10m $(\mathrm{m} / \mathrm{s})$ & $4,1 \pm 0,3$ & $5,0 \pm 0,2$ & 0,11 & $5,1 \pm 0,2$ & $5,0 \pm 0,3$ & 0,27 \\
\hline V30m $(\mathrm{m} / \mathrm{s})$ & $6,1 \pm 0,4$ & $6,2 \pm 0,2$ & 0,09 & $6,3 \pm 0,2$ & $6,3 \pm 0,3$ & 0,11 \\
\hline CMJ $(\mathrm{cm})$ & $33,8 \pm 5,0^{*}$ & $35,5 \pm 4,2$ & 0,04 & $35,3 \pm 3,2$ & $34,1 \pm 2,1$ & 0,18 \\
\hline
\end{tabular}

\section{Conclusões}

A partir dos dados coletados conclui-se que:

i) Houve predominância de treinamento neuromuscular sobre o funcional, destacadamente os estímulos nas capacidades de resistência especial e força especial, caracterizando um alto grau de especificidade com a modalidade;

ii) A partir da organização do treinamento adotada, durante o período de oito semanas, verificou-se diferença no comportamento das capacidades biomotoras analisadas nas diferentes categorias.

\section{Agradecimentos}

CNPq pela bolsa PIBIC;

As atletas e comissão técnica da equipe participante; Aos membros do Grupo de Estudo e Pesquisa em Teoria e Metodologia do Treinamento Desportivo FEF/UNICAMP.

GOMES, A. C., SOUZA, J., Futebol: treinamento desportivo de alto rendimento. Porto Alegre, RS: Artmed, 2008.

LITTLE, T., WILLIAMS, A. Specifity of acceleration, maximum speed, and agility in professional soccer players. Journal of Strenght and Conditioning Research, n. 19(1), p. 76-78, 2005 